\title{
Percepção dos docentes em relação à Avaliação do Docente pelo Discente
}

\author{
Teachers' Perception of Student assessment by Teacher
}

\author{
Aldiara Fernanda Pavão Garcia', Arioane Primon Soares", \\ Bianca de Oliveira Lovato"', Elisandra Lúcia Moro Stochero'v, \\ Luciane Clates Padilhav, Fernando de Jesus Moreira Junior ${ }^{\mathrm{VI}}$
}

\begin{abstract}
RESUMO
O objetivo desse trabalho foi avaliar a percepção dos Docentes da Universidade Federal de Santa Maria em relação à Avaliação Docente pelo Discente a fim de verificar deficiências e propor melhorias no processo avaliativo. Foi realizada uma análise do instrumento de Avaliação do Docente pelo Discente da instituição e, assim, elaborado um questionário enviado a todos os docentes aptos a participarem da pesquisa. Os resultados mostraram que a maioria dos docentes está satisfeita principalmente com o instrumento de avaliação, com a avaliação realizada pelos alunos e com a obrigatoriedade da aplicação. No entanto, há uma insatisfação significativa com o fato dos alunos não serem obrigados a responder, com a baixa adesão dos alunos e com a influência da avaliação na progressão docente.
\end{abstract}

Palavras-chave: Avaliação do Desempenho Docente; Universidade Federal de Santa Maria; Autoavaliação da Instituição; Pesquisa de Opinião.

\begin{abstract}
The objective of this work was to evaluate the perception of the Faculty of the Federal University of Santa Maria regarding the Teacher Evaluation by the Student in order to verify deficiencies and propose improvements in the evaluation process. An analysis was made of the Faculty's Student Assessment tool and, thus, a questionnaire was prepared sent to all teachers able to participate in the research. The results showed that most teachers are satisfied mainly with the assessment instrument, the assessment made by the students and the obligation of application. However, there is significant dissatisfaction with the fact that students are not required to respond, with poor student adherence and the influence of assessment on teacher progression.
\end{abstract}

Keywords: Teaching Performance Evaluation; Federal University of Santa Maria; Self-Assessment of the Institution; Survey Research.

\footnotetext{
' Universidade Federal de Santa Maria, Santa Maria, Brasil. E-mail: aldiarafernandagarcia@hotmail.com.

" Universidade Federal de Santa Maria, Santa Maria, Brasil. E-mail: arioane@gmail.com.

III Universidade Federal de Santa Maria, Santa Maria, Brasil. E-mail: biancalovato@outlook.com.

IV Universidade Federal de Santa Maria, Santa Maria, Brasil. E-mail: elisandra_sto@hotmail.com.

v Universidade Federal de Santa Maria, Santa Maria, Brasil. E-mail: lucianepadilha4@gmail.com.

v' Universidade Federal de Santa Maria, Santa Maria, Brasil. E-mail: fmjunior777@yahoo.com.br.
} 


\section{INTRODUÇÃO}

A implementação do instrumento de Avaliação do docente pelo Discente na Universidade Federal de Santa Maria (UFSM) é bastante recente. Sua aplicação com abrangência de todos os cursos técnicos e de graduação se iniciou no segundo semestre de 2016. Porém, desde 2013 está em vigor a determinação legal de que os discentes devem participar da avaliação de desempenho didático dos docentes para fins de progressão funcional. Essa medida está prevista no Art. 6ª inciso I, da Portaria N.554, de 20 de junho de 2013, que estabelece as diretrizes gerais para o processo de avaliação do desempenho de docentes de Instituições Federais de Ensino (BRASIL, 2013):

Art. 6o A avaliação para a progressão funcional na Classe $A$, com as denominações de Professor Adjunto A, Professor Assistente A, e Professor Auxiliar, Classe B, com a denominação de Professor Assistente, Classe C, com a denominação de Professor Adjunto e, Classe D, com a denominação de Professor Associado, levará em consideração, entre outros, os seguintes elementos:

I - Desempenho didático, avaliado com a participação do corpo discente (BRASIL, 2013, p. 10).

A Comissão Própria de Avaliação (CPA) que, conforme Art. 11 da Lei nº 10.861 de 14 de abril de 2004, é responsável institucional pela condução dos processos de avaliação internos da UFSM, atuando de forma autônoma em relação a conselhos e demais órgãos colegiados existentes na Instituição, estabeleceu que a primeira aplicação do instrumento de Avaliação do Docente pelo Discente em nível institucional ainda não teria impacto na progressão docente. A partir do momento que o instrumento passou a exercer influência na progressão funcional, além de permitir que os discentes manifestassem sugestões, opiniões, elogios ou críticas, os docentes passaram a expressar opiniões diversas a respeito da avaliação. Enquanto alguns se mostram muito satisfeitos com a nota e os elogios recebidos, outros estão descontentes, pois não foram bem avaliados e/ou receberam opiniões ou críticas que não concordam. Deste modo, a retirada de alguns pontos na progressão funcional dos professores parece ser um agravante para os que receberam notas baixas e avaliações negativas. 
Conforme Ribeiro (2011), os processos de avaliação se configuram em políticas públicas com grande capacidade para promover mudanças e adequações nos sistemas de ensino frente às demandas sociais. Além disso, o sistema de avaliação, sendo apresentado em forma da Lei 10.861/2004 que institui o Sistema Nacional de Avaliação da Educação Superior (SINAES), levou a um movimento nas Instituições de Ensino Superior (IES) para a composição das Comissões Próprias de Avaliação, para indicação dos seus respectivos representantes, elaboração dos projetos e relatórios de avaliação, exigindo a elaboração dos documentos institucionais que norteiam a vida acadêmica, tais como projeto político pedagógico, plano de desenvolvimento institucional e estabelecimento da missão institucional. Porém, o maior ganho institucional está na proposição de um modelo de gestão baseado no planejamento estratégico, que surge quase que naturalmente à medida que as IES adotam as diretrizes de avaliação do SINAES.

Com o objetivo de regulamentar os procedimentos de avaliação do Sistema Nacional de Avaliação da Educação Superior (SINAES), foi criada a portaria No 2.051, de 9 de julho de 2004. Através do SINAES busca-se a melhoria da qualidade da educação superior, por intermédio de um sistema que visa promover a avaliação das instituições de ensino superior, dos cursos de graduação e desempenho dos estudantes sob a coordenação e supervisão da Comissão Nacional de Avaliação da Educação Superior (CONAES). Ainda, conforme o cap. III da portaria N².051, a avaliação de instituições é executada de acordo com as diretrizes estabelecidas pela CONAES e as avaliações externas são designadas pelo INEP que por sua vez deve realizar periodicamente programas de capacitação dos avaliadores que compõem as comissões de avaliação, sob orientação da CONAES.

As Comissões Próprias de Avaliação (CPAs), previstas no Art. 11 da Lei no 10.861, de 14 de abril de 2004, e constituídas no âmbito de cada instituição de educação superior, tratam da coordenação dos processos internos de avaliação da instituição, de sistematização e de prestação das informações solicitadas pelo INEP. A CPA desempenha um papel determinante no processo de melhoria da qualidade do ensino nas IES brasileiras e o resultado da autoavaliação institucional, coordenada e aplicada 
pela CPA, indica os pontos fortes e os pontos fracos do ambiente interno da IES. A partir dos resultados da pesquisa institucional, os gestores obtêm parâmetros que servirão de base para a tomada de decisão e para o desenvolvimento do planejamento estratégico da instituição (MOTA, 2016, p. 19).

O processo de melhoria contínua da qualidade da educação nas IES, atendendo as exigências e critérios do MEC, em que a CPA é um dos principais atores, tem grande importância também para a sociedade, pois as IES formam os profissionais que irão colaborar para o desenvolvimento do Brasil e que dependem de uma educação de qualidade. A qualidade dos serviços só pode ser avaliada por meio da percepção das pessoas no ato da sua entrega, já que os serviços são intangíveis e a sua avaliação vai depender da expectativa dos consumidores em relação ao serviço prestado. Se o serviço superar as suas expectativas e o consumidor ficar satisfeito, com certeza a instituição estará prestando um serviço de qualidade (MOTA, 2016, p. 19).

Neste contexto, e com base na Lei 10.861 de 14 de abril e 2004 e nas portarias 2.051/2004 e 554/2013 do Ministério da Educação, que estabelecem as diretrizes gerais para o processo de avaliação de desempenho de servidores pertencentes ao Plano de Carreiras e Cargos de Magistério Federal das Instituições Federais de Ensino vinculadas ao MEC, foi criada a Avaliação do Docente pelo Discente. Além disso, vem ao encontro de tal determinação, a busca constante pelo aperfeiçoamento da qualidade de ensino oferecido na UFSM.

Na UFSM, a Comissão Própria de Avaliação (CPA) tem por responsabilidade a condução dos processos de avaliação internos da Instituição, atuando de forma autônoma em relação a conselhos e demais órgãos colegiados existentes na Instituição. A CPA tem o auxílio operacional e administrativo da Coordenadoria de Planejamento e Avaliação Institucional (COPLAl), vinculada à Pró- Reitoria de Planejamento (PROPLAN), bem como o auxílio da Comissão Setorial de Avaliação (CSA) de cada Unidade da UFSM. O processo de avaliação do Docente pelo Discente já vem sendo aplicado em outras instituições de ensino, como na Universidade Tecnológica Federal do Paraná (UTFPR), Campus Curitiba, onde plataforma do Sistema de Avaliação Institucional - SIAVI - a cada ano vem apresentando evolução significativa de melhorias 
no processo, contando com o apoio dos recursos "midiáticos" disponíveis nas redes de web. Esse vem sendo caracterizado pelo bom desempenho, funcionamento e dedicação de profissionais na realização dos processos de avaliação na instituição (MATUICHUK; SILVA, 2013).

A comunidade docente da UFSM tem manifestado opiniões diversas referentes à avaliação do docente pelo discente. Muitos se mostram insatisfeitos mediante o impacto dessa avaliação na progressão docente, outros ainda não admitem ser avaliados ou não sentem necessidade de mudanças nas metodologias utilizadas nas aulas. O que de fato parece não ter sido compreendido por alguns docentes é que Avaliação do Docente pelo Discente surgiu como uma proposta que visa colaborar com melhoria da qualidade do ensino. Nesse contexto, este estudo visa avaliar a percepção dos docentes da UFSM com relação à Avaliação do Docente pelo Discente.

\section{METODOLOGIA}

Com base no instrumento da Avaliação do Docente pelo Discente da UFSM, elaborou-se um questionário para obter-se a opinião dos docentes com relação à esse instrumento de avaliação. O questionário possuía três pequenos blocos de questões relacionadas: (1) à lotação e tempo de trabalho do docente na UFSM, (2) às opiniões dos docentes e fatos ocorridos relacionados com a avaliação com duas categorias de resposta sim/não, e (3) à satisfação dos docentes com relação à vários aspectos da avaliação, por meio de uma escala likert de satisfação com quatro categorias de respostas: muito insatisfeito, insatisfeito, satisfeito e muito satisfeito. Optou-se por não utilizar categorias intermediárias, como "em parte" ou "não concordo nem discordo" para evitar que o respondente permaneça na zona de conforto ou dúvida e se posicione com relação ao item avaliado (MALHOTRA, 2012). No final do questionário, foi disponibilizado um espaço para o docente deixar comentários, a fim de captar sugestões, opiniões, elogios ou críticas.

A coleta dos dados ocorreu no segundo semestre de 2017. O questionário foi disponibilizado de forma eletrônica pelo sistema de questionários do Centro de Processamento de Dados (CPD) da UFSM a todos os docentes de todos os campi da UFSM que foram avaliados pelo menos uma vez na Avaliação do Docente pelo Discente 
da UFSM nas primeiras três avaliações realizadas (primeiro semestre de 2016, segundo semestre de 2016 e primeiro semestre de 2017) e que concordaram em participar voluntariamente da pesquisa. Os respondentes receberam o convite para responder à pesquisa via e-mail, mas também foram publicados comunicados no site oficial a UFSM. Ao acessar o link da pesquisa, o respondente deveria ler o Termo de Consentimento Livre e Esclarecido (TCLE) e aceitá-lo, caso concordasse com o mesmo, para participar da pesquisa. Mesmo assim, era assegurado aos participantes o direito de desistir a qualquer momento ou não participar da pesquisa sem quaisquer represálias atuais ou futuras, além da garantia de que não seriam identificados na pesquisa. O projeto da pesquisa foi registrado no Gabinete de Projetos (GAP) do Centro de Ciências Naturais e Exatas (CCNE) da UFSM sob o número 58454 e aprovado pelo parecer consubstanciado número 2.325.904 do Comitê de Ética em Pesquisa ( $n^{\circ}$ CAAE 77825517.0.0000.5346).

No presente estudo foi utilizada uma amostra não probabilística por conveniência, utilizando-se dos indivíduos mais acessíveis e cooperadores da população, que atendam ao convite da pesquisa, como é o caso das pesquisas pela internet. Algumas vantagens da utilização da internet na aplicação do questionário são: maior alcance, economia de tempo, baixo custo, facilidade de coleta e tabulação dos dados. Como já mencionado, população alvo os docentes de todos os campi da UFSM que foram avaliados pelo menos uma vez na referida avaliação. Dessa forma, de um total de 1.964 docentes, 1679, ou seja, 85,5\% estavam aptos a participar. Segundo McDaniel e Gates (2005), os índices de resposta das pesquisas aplicadas por meio da internet variam entre $30 \%$ e $60 \%$, no entanto, obteve-se uma taxa de retorno de $20,6 \%$, totalizando 346 respondentes. A análise dos dados foi feita por meio de estatística descritiva, com a elaboração de gráficos e tabelas, cálculo de percentuais e de médias, utilizando-se o software Excel.

\section{RESULTADOS E DISCUSSÃO}

A Tabela 1 apresenta a quantidade de docentes e de participantes da pesquisa por Unidade (Centro ou Campus) da UFSM, além do percentual de participação e o tempo médio de serviço (em anos) dos participantes. Observa-se que o percentual 
Garcia, A. F. P., Soares, A. P., Lovato, B. de O., Stochero, E. L. M., Padilha, L. C., Moreira Junior, F. de J. 7

médio de participação geral foi de 20,6\%, no entanto, destacam-se as participações do CTISM (45,0\%), do Campus Cachoeira $(41,8 \%)$ e do CCNE $(28,8 \%)$. No entanto, esperavase uma participação maior da comunidade docente da UFSM pelo fato da pesquisa ter sido amplamente divulgada via e-mail e no site oficial da UFSM por duas vezes.

A Tabela 2 apresenta as respostas (em percentual) das questões do questionário relacionadas com os comentários dos alunos na avaliação, por Unidade/Campus e geral.

Tabela 1 - Participantes por Unidade/Campus e tempo médio de serviço

\begin{tabular}{|c|c|c|c|c|}
\hline Unidades/Campus UFSM & $\begin{array}{c}\text { Total de } \\
\text { Docentes** }\end{array}$ & $\begin{array}{l}\text { Total de } \\
\text { respondentes }\end{array}$ & $\begin{array}{l}\text { Percentual de } \\
\text { participação }\end{array}$ & $\begin{array}{l}\text { Tempo médio de } \\
\text { serviço (em anos) }\end{array}$ \\
\hline CAL - Centro de Artes e Letras & 134 & 23 & 17,2 & 8,7 \\
\hline $\begin{array}{l}\text { CCNE - Centro de Ciências Naturais } \\
\text { e Exatas }\end{array}$ & 225 & 64 & 28,4 & 12,3 \\
\hline CCR - Centro de Ciências Rurais & 197 & 42 & 21,3 & 12,3 \\
\hline CCS - Centro de Ciências da Saúde & 285 & 44 & 15,4 & 12,4 \\
\hline $\begin{array}{l}\text { CCSH - Centro de Ciências Sociais e } \\
\text { Humanas }\end{array}$ & 223 & 37 & 16,6 & 9,4 \\
\hline CE - Centro de Educação & 104 & 19 & 18,3 & 7,4 \\
\hline $\begin{array}{l}\text { CEFD - Centro de Educação Física e } \\
\text { Desporto }\end{array}$ & 34 & 8 & 23,5 & 14,9 \\
\hline CT - Centro de Tecnologia & 199 & 30 & 15,1 & 7,3 \\
\hline $\begin{array}{l}\text { CTISM - Colégio Técnico Industrial } \\
\text { de Santa Maria }\end{array}$ & 20 & 9 & 45,0 & 9,0 \\
\hline Colégio Politécnico & 31 & 7 & 22,6 & 6,1 \\
\hline Campus de Cachoeira do Sul & 55 & 23 & 41,8 & 2,0 \\
\hline Campus de Frederico Westphalen & 87 & 21 & 24,1 & 5,2 \\
\hline Campus de Palmeira das Missões & 84 & 18 & 21,4 & 6,0 \\
\hline $\begin{array}{l}\text { UDESSM* }{ }^{*}- \\
\text { Descentralizada } \\
\text { de Ensino Superior de Silveira } \\
\text { Martins }\end{array}$ & 1 & 1 & 100,0 & 11,0 \\
\hline Total & 1.679 & 346 & 20,6 & 9,5 \\
\hline
\end{tabular}


Tabela 2 - Questões relacionadas com os comentários dos alunos na avaliação (percentual considerando as respostas válidas)

\begin{tabular}{|c|c|c|c|c|c|c|c|c|c|c|}
\hline \multirow[t]{2}{*}{$\begin{array}{l}\text { Unidades/ } \\
\text { Campus UFSM }\end{array}$} & \multicolumn{2}{|c|}{$\begin{array}{l}\text { Seus alunos } \\
\text { expuseram alguma } \\
\text { sugestão, opinião, } \\
\text { elogio ou crítica? }\end{array}$} & \multicolumn{2}{|c|}{$\begin{array}{c}\text { Você achou relevantes } \\
\text { as sugestões, } \\
\text { opiniões, elogios ou } \\
\text { críticas que recebeu? }\end{array}$} & \multicolumn{2}{|c|}{$\begin{array}{l}\text { Você recebeu } \\
\text { elogios na } \\
\text { avaliação dos } \\
\text { discentes? }\end{array}$} & \multicolumn{2}{|c|}{$\begin{array}{l}\text { Você recebeu } \\
\text { críticas na } \\
\text { avaliação dos } \\
\text { discentes? }\end{array}$} & \multicolumn{2}{|c|}{$\begin{array}{l}\text { Você recebeu } \\
\text { críticas que você } \\
\text { não concordou? }\end{array}$} \\
\hline & Sim & Não & Sim & Não & Sim & Não & Sim & Não & Sim & Não \\
\hline CAL & $82,6 \%$ & $17,4 \%$ & $73,7 \%$ & $26,3 \%$ & $94,7 \%$ & $5,3 \%$ & $78,9 \%$ & $21,1 \%$ & $80,0 \%$ & $20,0 \%$ \\
\hline CCNE & $84,4 \%$ & $15,6 \%$ & $79,6 \%$ & $20,4 \%$ & $90,7 \%$ & $9,3 \%$ & $79,6 \%$ & $20,4 \%$ & $67,4 \%$ & $32,6 \%$ \\
\hline CCR & $76,2 \%$ & $23,8 \%$ & $87,5 \%$ & & $100,0 \%$ & $0,0 \%$ & $87,5 \%$ & $12,5 \%$ & $85,7 \%$ & $14,3 \%$ \\
\hline CCS & $56,8 \%$ & $43,2 \%$ & $88,0 \%$ & $12,0 \%$ & $100,0 \%$ & $0,0 \%$ & $96,0 \%$ & $4,0 \%$ & $87,5 \%$ & $12,5 \%$ \\
\hline $\mathrm{CCSH}$ & $73,0 \%$ & $27,0 \%$ & $88,9 \%$ & $11,1 \%$ & $92,6 \%$ & $7,4 \%$ & $70,4 \%$ & $29,6 \%$ & $84,2 \%$ & $15,8 \%$ \\
\hline CE & $84,2 \%$ & $15,8 \%$ & $87,5 \%$ & $12,5 \%$ & $100,0 \%$ & $0,0 \%$ & $87,5 \%$ & $12,5 \%$ & $71,4 \%$ & $28,6 \%$ \\
\hline CEFD & $62,5 \%$ & $37,5 \%$ & $100,0 \%$ & $0,0 \%$ & $100,0 \%$ & $0,0 \%$ & $80,0 \%$ & $20,0 \%$ & $25,0 \%$ & $75,0 \%$ \\
\hline $\mathrm{CT}$ & $83,3 \%$ & $16,7 \%$ & $84,0 \%$ & $16,0 \%$ & $92,0 \%$ & $8,0 \%$ & $100,0 \%$ & $0,0 \%$ & $72,0 \%$ & $28,0 \%$ \\
\hline CTISM & $66,7 \%$ & $33,3 \%$ & $83,3 \%$ & $16,7 \%$ & $100,0 \%$ & $0,0 \%$ & $83,3 \%$ & $16,7 \%$ & $40,0 \%$ & $60,0 \%$ \\
\hline Col. Politécnico & $71,4 \%$ & $28,6 \%$ & $100,0 \%$ & $0,0 \%$ & $100,0 \%$ & $0,0 \%$ & $100,0 \%$ & $0,0 \%$ & $100,0 \%$ & $0,0 \%$ \\
\hline C. Cachoeira S. & $87,0 \%$ & $13,0 \%$ & $75,0 \%$ & $25,0 \%$ & $100,0 \%$ & $0,0 \%$ & $90,0 \%$ & $10,0 \%$ & $83,3 \%$ & $16,7 \%$ \\
\hline C. Frederico W. & $66,7 \%$ & $33,3 \%$ & $100,0 \%$ & $0,0 \%$ & $100,0 \%$ & $0,0 \%$ & $71,4 \%$ & $28,6 \%$ & $80,0 \%$ & $20,0 \%$ \\
\hline C. Palmeiras M. & $88,9 \%$ & $11,1 \%$ & $87,5 \%$ & $12,5 \%$ & $100,0 \%$ & $0,0 \%$ & $93,8 \%$ & $6,3 \%$ & $73,3 \%$ & $26,7 \%$ \\
\hline UFSM Geral & $76,3 \%$ & $23,7 \%$ & $84,8 \%$ & $15,2 \%$ & $96,2 \%$ & $3,8 \%$ & $85,2 \%$ & $14,8 \%$ & $76,4 \%$ & $23,6 \%$ \\
\hline
\end{tabular}

Fonte: Elaboração própria.

Cerca de 76,3\% dos docentes receberam algum comentário dos alunos, e desses, $84,8 \%$ consideram os comentários relevantes. Dentre os docentes que não consideraram relevantes os comentários (15,2\%), 26,3\% pertenciam ao CAL, 25,5\% ao Campus de Cachoeira e 20,4\% ao CCNE.

Dentre comentários dos alunos comentários recebidos, 96,2\% receberam elogios e $85,2 \%$ receberam críticas, porém $76,4 \%$ dos docentes criticados não concordaram com as críticas recebidas. Esse é um dado relevante, o qual mostra a diferença do olhar do docente e do discente com relação à avaliação. Evidencia-se aqui uma falta de concordância e de entendimento entre professores e alunos que deve ser investigada com maior profundidade. A exceção fica por conta dos docentes do CEFD e do CTISM, onde a maioria concorda com as críticas recebidas pelos alunos.

A Tabela 3 apresenta as respostas (em percentual) das questões do questionário relacionadas com a participação dos alunos e seu desempenho, com a publicação dos seus comentários e com a participação do docente na consulta pública, por Unidade/Campus e geral. 
Tabela 3 - Questões relacionadas com a participação dos alunos e seu desempenho, com a publicação dos seus comentários e com a participação do docente na consulta pública (percentual considerando as respostas válidas)

\begin{tabular}{|c|c|c|c|c|c|c|c|c|c|c|}
\hline \multirow[t]{2}{*}{$\begin{array}{l}\text { Unidades/ } \\
\text { Campus } \\
\text { UFSM }\end{array}$} & \multicolumn{2}{|c|}{$\begin{array}{l}\text { Você incentiva os } \\
\text { seus alunos a } \\
\text { participarem da } \\
\text { avaliação docente } \\
\text { pelo discente? }\end{array}$} & \multicolumn{2}{|c|}{$\begin{array}{l}\text { Você acha que o } \\
\text { desempenho do } \\
\text { aluno na } \\
\text { disciplina } \\
\text { influencia na } \\
\text { avaliação? }\end{array}$} & \multicolumn{2}{|c|}{$\begin{array}{l}\text { Você acha que os } \\
\text { alunos } \\
\text { respondem à } \\
\text { avaliação com } \\
\text { seriedade? }\end{array}$} & \multicolumn{2}{|c|}{$\begin{array}{c}\text { Você acha que } \\
\text { sugestões, opiniões, } \\
\text { elogios ou críticas } \\
\text { poderiam vir a ser } \\
\text { divulgados } \\
\text { publicamente? }\end{array}$} & \multicolumn{2}{|c|}{$\begin{array}{l}\text { Você participou da } \\
\text { consulta pública } \\
\text { sobre o } \\
\text { instrumento, } \\
\text { realizada pela } \\
\text { CPA/UFSM? }\end{array}$} \\
\hline & Sim & Não & Sim & Não & Sim & Não & Sim & Não & Sim & Não \\
\hline CAL & $95,7 \%$ & $4,3 \%$ & $78,3 \%$ & $21,7 \%$ & $65,2 \%$ & $34,8 \%$ & $39,1 \%$ & $60,9 \%$ & $52,2 \%$ & $47,8 \%$ \\
\hline CCNE & $90,6 \%$ & $9,4 \%$ & $89,1 \%$ & $10,9 \%$ & $56,3 \%$ & $43,8 \%$ & $34,4 \%$ & $65,6 \%$ & $42,2 \%$ & $57,8 \%$ \\
\hline CCR & $95,2 \%$ & $4,8 \%$ & $90,5 \%$ & $9,5 \%$ & $45,2 \%$ & $54,8 \%$ & $38,1 \%$ & $61,9 \%$ & $42,9 \%$ & $57,1 \%$ \\
\hline CCS & $88,6 \%$ & $11,4 \%$ & $93,2 \%$ & $6,8 \%$ & $59,1 \%$ & $40,9 \%$ & $22,7 \%$ & $77,3 \%$ & $25,0 \%$ & $75,0 \%$ \\
\hline $\mathrm{CCSH}$ & $81,1 \%$ & $18,9 \%$ & $75,7 \%$ & $24,3 \%$ & $59,5 \%$ & $40,5 \%$ & $27,0 \%$ & $73,0 \%$ & $43,2 \%$ & $56,8 \%$ \\
\hline CE & $94,7 \%$ & $5,3 \%$ & $84,2 \%$ & $15,8 \%$ & $68,4 \%$ & $31,6 \%$ & $31,6 \%$ & $68,4 \%$ & $63,2 \%$ & $36,8 \%$ \\
\hline CEFD & $87,5 \%$ & $12,5 \%$ & $87,5 \%$ & $12,5 \%$ & $62,5 \%$ & $37,5 \%$ & $62,5 \%$ & $37,5 \%$ & $50,0 \%$ & $50,0 \%$ \\
\hline $\mathrm{CT}$ & $90,0 \%$ & $10,0 \%$ & $93,3 \%$ & $6,7 \%$ & $50,0 \%$ & $50,0 \%$ & $53,3 \%$ & $46,7 \%$ & $43,3 \%$ & $56,7 \%$ \\
\hline CTISM & $88,9 \%$ & $11,1 \%$ & $100,0 \%$ & $0,0 \%$ & $11,1 \%$ & $88,9 \%$ & $22,2 \%$ & $77,8 \%$ & $77,8 \%$ & $22,2 \%$ \\
\hline $\begin{array}{l}\text { Col. } \\
\text { Politécnico }\end{array}$ & $100,0 \%$ & $0,0 \%$ & $85,7 \%$ & $14,3 \%$ & $71,4 \%$ & $28,6 \%$ & $28,6 \%$ & $71,4 \%$ & $71,4 \%$ & $28,6 \%$ \\
\hline $\begin{array}{l}\text { C. Cachoeira } \\
\text { S. }\end{array}$ & $91,3 \%$ & $8,7 \%$ & $100,0 \%$ & $0,0 \%$ & $47,8 \%$ & $52,2 \%$ & $17,4 \%$ & $82,6 \%$ & $30,4 \%$ & $69,6 \%$ \\
\hline $\begin{array}{l}\text { C. Frederico } \\
\text { W. }\end{array}$ & $100,0 \%$ & $0,0 \%$ & $95,2 \%$ & $4,8 \%$ & $33,3 \%$ & $66,7 \%$ & $28,6 \%$ & $71,4 \%$ & $52,4 \%$ & $47,6 \%$ \\
\hline $\begin{array}{l}\text { C. Palmeiras } \\
\text { M. }\end{array}$ & $88,9 \%$ & $11,1 \%$ & $72,2 \%$ & $27,8 \%$ & $50,0 \%$ & $50,0 \%$ & $44,4 \%$ & $55,6 \%$ & $44,4 \%$ & $55,6 \%$ \\
\hline UFSM Geral & $91,0 \%$ & $9,0 \%$ & $88,2 \%$ & $11,8 \%$ & $53,2 \%$ & $46,8 \%$ & $33,8 \%$ & $66,2 \%$ & $43,6 \%$ & $56,4 \%$ \\
\hline
\end{tabular}

Dos 346 docentes que responderam a pesquisa, a maioria $(91,0 \%)$ incentiva os alunos a participarem da avaliação docente pelo discente. Porém, a preocupação aqui se dá com relação aos docentes que não incentivam seus alunos, principalmente com docentes do CCSH, onde 18,9\% não incentivam seus alunos.

A grande maioria dos docentes (88,2\%) acredita que o desempenho do aluno na disciplina influencia na avaliação docente. Essa percepção deve ser investigada, pois a avaliação docente pelo discente não deveria ser influenciada pelo desempenho do próprio aluno.

Outro resultado preocupante é que quase metade dos docentes $(46,8 \%)$, principalmente do CTISM e do Campus de Frederico Westphalen, acha que os alunos não respondem a avaliação com seriedade. Se realmente existe uma quantidade tão grande de alunos que não levam a sério a pesquisa, então boa parte dos resultados não seria confiável. Isso é algo que deve ser investigado. 
A maioria dos docentes $(66,2 \%)$ não concorda com a divulgação pública desses dos comentários que os alunos expõem na avaliação. O motivo para a não divulgação pode ser pelo fato que a maioria dos docentes criticados $(76,4 \%)$ não concordam com as críticas recebidas, conforme a Tabela 2.

A pesquisa revelou que $43,6 \%$ dos respondentes, principalmente do CTISM, do Colégio Politécnico e do $\mathrm{CE}$, participaram da consulta pública sobre a formulação do instrumento de avaliação docente pelo discente, sendo considerado um percentual relevante de participação docente. Docentes do CCS e do Campus de Cachoeira do Sul foram os que menos participaram.

A Figura 1 apresenta o resultado geral da UFSM (em percentual) das respostas às questões do questionário para avaliar a satisfação dos docentes com relação à vários aspectos da avaliação. A Tabela 4 apresenta esses resultados agrupando as categorias "satisfeito" com "totalmente satisfeito" e "insatisfeito" com "totalmente insatisfeito", por Unidade e Campus da UFSM.

Figura 1 - Percentual de respostas com relação à satisfação (considerando apenas as respostas válidas)

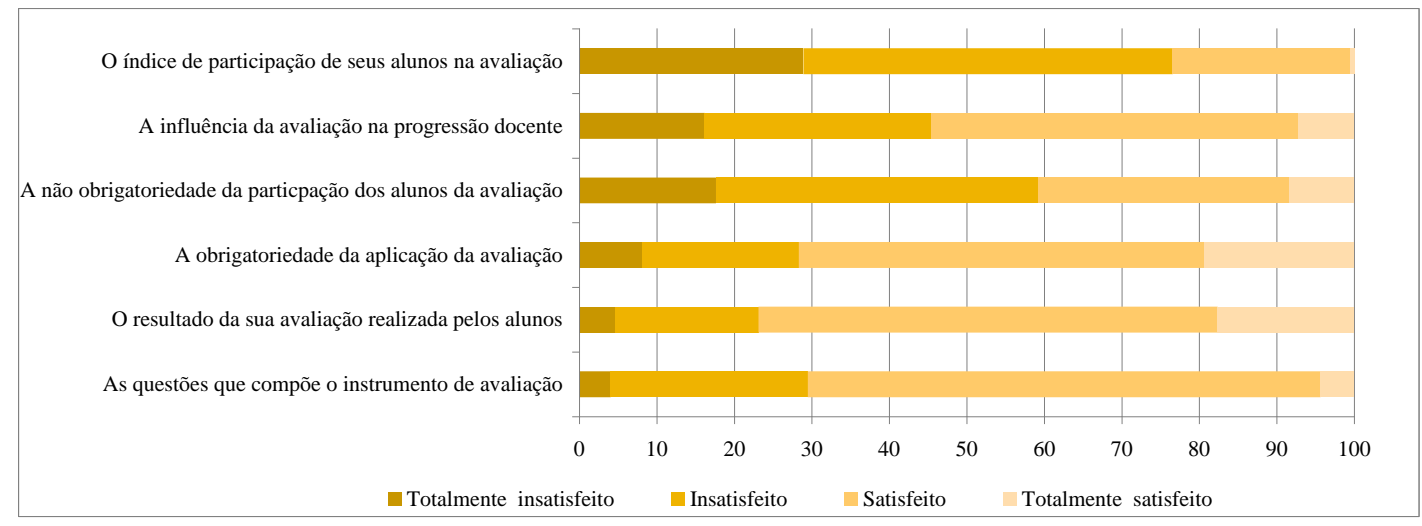

Quanto ao instrumento de avaliação, 70,5\% se mostraram satisfeitos e 29,4\% insatisfeitos. O maior índice de insatisfação foi registrado entre os docentes do CTISM $(55,6 \%)$.

Quanto à avaliação realizada pelos alunos, $76,8 \%$ se mostraram satisfeitos e $23,1 \%$ insatisfeitos. O maior índice de insatisfação foi novamente registrado entre os docentes do CTISM (55,6\%). Apesar do grande índice entre os docentes que receberam 
críticas que não concordaram (76,4\%), conforme a Tabela 2, a maioria se mostrou satisfeita quanto à avaliação dos alunos, sendo um resultado que surpreendeu.

Quanto à obrigatoriedade da aplicação da avaliação, 71,7\% se mostraram satisfeitos e $28,3 \%$ insatisfeitos. Ressalta-se que essa avaliação é obrigatória por lei, conforme Brasil (2013, p. 10).

Quanto ao fato dos alunos não serem obrigados a responder o instrumento, $40,8 \%$ se mostraram satisfeitos e $59,2 \%$ insatisfeitos. Os docentes que estão mais satisfeitos são os do Colégio Politécnico $(71,4 \%)$, do CE $(68,4 \%)$, do Campus de Cachoeira do Sul $(60,9 \%)$ e do CAL (56,5\%). Por outro lado, os docentes que estão mais insatisfeitos são os do $\operatorname{CEFD}(75,0 \%)$, do $\operatorname{CCR}(73,8 \%)$, do $\operatorname{CCS}(72,7 \%)$, do Campus Palmeiras das Missões (72,2\%), do CT (70,0\%) e do CTISM (66,7\%) Isso mostra que a maioria dos docentes da UFSM gostaria que todos os alunos fossem obrigados a responder essa avaliação. No entanto, não há meios legais de obrigar os alunos a participarem dessa avaliação.

Quanto à influência da avaliação docente pelo discente na progressão docente, $54,6 \%$ se mostraram satisfeitos e $45,4 \%$ insatisfeitos. Esse percentual de insatisfeitos chega a $64,9 \%$ no CCSH e 54,5\% no CCS. Apesar do elevado percentual de insatisfação, está previsto na lei que a avaliação dos discentes deve ser considerada na progressão docente, conforme Brasil (2013, p. 10).

Quanto ao índice de participação dos seus alunos, 23,4\% se mostraram satisfeitos e $76,6 \%$ insatisfeitos. Apenas o CE registrou um percentual de satisfação mais elevado $(47,4 \%)$, por outro lado, todos os docentes do Campus Palmeiras das Missões que participaram da pesquisa mostraram-se insatisfeitos com o índice de participação dos seus alunos. 
Tabela 4 - Percentual de respostas com relação à satisfação (considerando apenas as respostas válidas)

\begin{tabular}{|c|c|c|c|c|c|c|c|c|c|c|c|c|}
\hline & \multicolumn{2}{|c|}{$\begin{array}{c}\text { As questões } \\
\text { que compõe } \\
\text { o instrumento } \\
\text { de avaliação }\end{array}$} & \multicolumn{2}{|c|}{$\begin{array}{l}\text { O resultado } \\
\text { da sua } \\
\text { avaliação } \\
\text { realizada } \\
\text { pelos alunos }\end{array}$} & \multicolumn{2}{|c|}{$\begin{array}{c}\text { A } \\
\text { obrigatoriedade } \\
\text { da aplicação } \\
\text { da avaliação }\end{array}$} & \multicolumn{2}{|c|}{$\begin{array}{c}\text { A não } \\
\text { obrigatoriedade } \\
\text { da participação } \\
\text { dos alunos } \\
\text { da avaliação }\end{array}$} & \multicolumn{2}{|c|}{$\begin{array}{c}\text { A influência } \\
\text { da avaliação } \\
\text { na progressão } \\
\text { docente }\end{array}$} & \multicolumn{2}{|c|}{$\begin{array}{c}\text { O índice de } \\
\text { participação de } \\
\text { seus alunos } \\
\text { na avaliação }\end{array}$} \\
\hline & Sat. & nsat. & Sat. & Insat. & Sat. & Insat. & Sat. & Insat. & Sat. & Insat. & Sat. & Insat. \\
\hline $\mathrm{AL}$ & & & $87,0 \%$ & $13,0 \%$ & & & $56,5 \%$ & & & & & \\
\hline CNE & 7 & & & & & & & & & $4 \%$ & $1 \%$ & \\
\hline CR & 6 & $3 \%$ & $71,4 \%$ & 28,6 & & & $26,2 \%$ & 73,8\% & $50,0 \%$ & $50,0 \%$ & $16,7 \%$ & \\
\hline CS &, $9 \%$ & $1,1 \%$ & $70,5 \%$ & $29,5 \%$ & 75, & & $27,3 \%$ & $72,7 \%$ & $45,5 \%$ & $54,5 \%$ & $11,4 \%$ & \\
\hline $\mathrm{CSSH}$ & & & $\%$ & $29,7 \%$ & $67,6 \%$ & & $45,9 \%$ & $54,1 \%$ & & $64,9 \%$ & $21,6 \%$ & \\
\hline$E$ & 7 & $1 \%$ & $4,2 \%$ & 15,8 & 63,2 & & $68,4 \%$ &, $6 \%$ & $73,7 \%$ & $26,3 \%$ & $47,4 \%$ & \\
\hline EFD & 7 & $0 \%$ & $75,0 \%$ & $25,0 \%$ & $75,0 \%$ & & $25,0 \%$ & $75,0 \%$ & 50, & $50,0 \%$ & $12,5 \%$ & \\
\hline & 6 & ,3\% & $76,7 \%$ & $23,3 \%$ & $76,7 \%$ & & $30,0 \%$ & $70,0 \%$ & & $33,3 \%$ & $26,7 \%$ & \\
\hline TISM & $44,4 \%$ &, $6 \%$ & $44,4 \%$ & $55,6 \%$ & $66,7 \%$ & & $33,3 \%$ & $66,7 \%$ & $55,6 \%$ & $44,4 \%$ & $33,3 \%$ & $66,7 \%$ \\
\hline $\begin{array}{l}\text { Col. } \\
\text { olitécnico }\end{array}$ & $71,4 \%$ & $28,6 \%$ & $85,7 \%$ & $14,3 \%$ & $85,7 \%$ & $14,3 \%$ & $71,4 \%$ & $28,6 \%$ & $85,7 \%$ & $14,3 \%$ & $28,6 \%$ & $71,4 \%$ \\
\hline $\begin{array}{l}\text { Cachoeira } \\
\text { S. }\end{array}$ & $73,9 \%$ & $26,1 \%$ & $65,2 \%$ & $34,8 \%$ & $65,2 \%$ & & $60,9 \%$ & $39,1 \%$ & $52,2 \%$ & $47,8 \%$ & $26,1 \%$ & $73,9 \%$ \\
\hline $\begin{array}{l}\text { C. Frederico } \\
\text { W. }\end{array}$ & $85,7 \%$ & $14,3 \%$ & $95,2 \%$ & $4,8 \%$ & $66,7 \%$ & $33,3 \%$ & $47,6 \%$ & $52,4 \%$ & $66,7 \%$ & $33,3 \%$ & $28,6 \%$ & $71,4 \%$ \\
\hline $\begin{array}{l}\text { Palmeiras } \\
\text { M. }\end{array}$ & $72,2 \%$ & $27,8 \%$ & $83,3 \%$ & $16,7 \%$ & $77,8 \%$ & $22,2 \%$ & $27,8 \%$ & $72,2 \%$ & $77,8 \%$ & $22,2 \%$ & $0,0 \%$ & $100,0 \%$ \\
\hline UFSM Geral & | 70,5\% & $29,5 \%$ & $76,9 \%$ & $23,1 \%$ & $71,7 \%$ & $28,3 \%$ & $40,8 \%$ & $59,2 \%$ & $54,6 \%$ & $45,4 \%$ & $23,4 \%$ & $76,6 \%$ \\
\hline
\end{tabular}

Fonte: Elaboração própria.

Nessa pesquisa, os docentes puderam também expressar suas percepções com relação à avaliação docente pelo discente no espaço disponibilizado para comentários. Dentre os participantes da pesquisa, 224 (64,7\%) expuseram comentários sobre vários aspectos da avaliação docente pelo discente. Os diversos assuntos foram analisados e agrupados por similaridade. A Figura 2 apresenta a frequência absoluta das expressões ou assuntos mais citados nos comentários realizados pelos docentes. 
Figura 2 - Expressões ou assuntos mais citados nos comentários da pesquisa

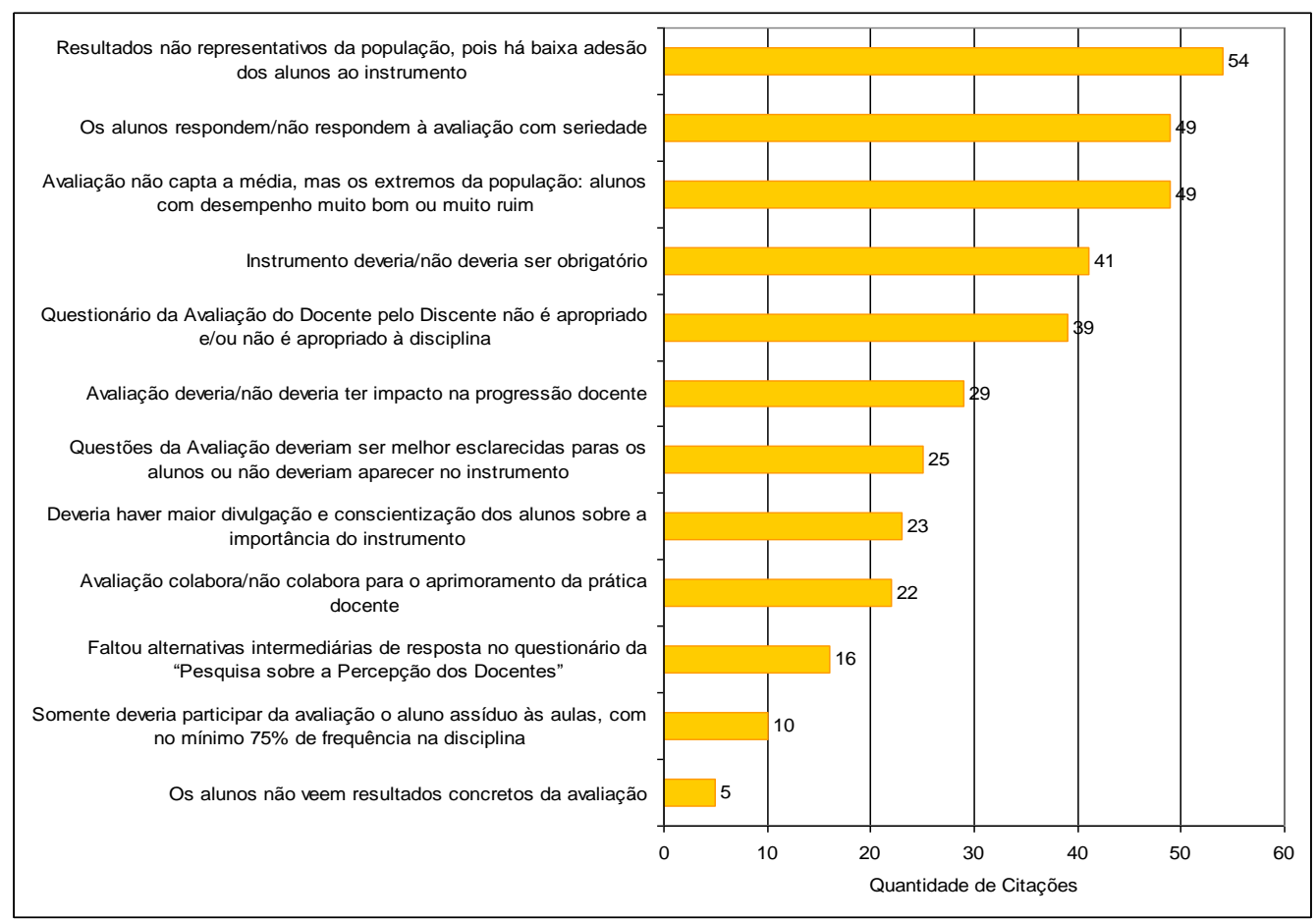

O aspecto mais abordado pelos professores que responderam ao questionário dessa pesquisa foi a falta de representatividade dos resultados da avaliação docente, com 54 comentários. Isso está diretamente relacionado com o elevado percentual de docentes insatisfeitos $(76,6 \%)$ quanto ao índice de participação dos seus alunos, conforme a Tabela 4. Como a participação não é obrigatória, muitas vezes o índice é baixo, consequentemente, a avaliação não seria adequada para ser utilizada na progressão docente, por exemplo. Além disso, segundo os professores, os alunos com mau desempenho, que ficaram em exame ou que reprovaram nas disciplinas, tanto por nota, quanto por frequência, são os que mais participam da avaliação, utilizando-a como forma de "se vingar" do professor da disciplina. Foram comentados casos de docentes que relataram ter recebido críticas ofensivas, agressivas, caluniosas, mentirosas e exageradas. Por outro lado, foi mencionado também que professores que "facilitam" a aprovação dos alunos são melhores avaliados do que professores que são mais rigorosos nas suas avaliações. Esses seriam motivos pelo qual $88,2 \%$ dos docentes que acreditam que o desempenho do aluno na disciplina influencia na avaliação docente, conforme Tabela 3. Ainda, segundo os comentários, alunos com bom desempenho e sem críticas a fazer não participam da avaliação. 
A falta de seriedade com que os alunos respondem a avaliação foi comentada 49 vezes. Conforme a Tabela 3, 46,8\% dos docentes participantes da pesquisa acreditam nisso. Consequentemente, o resultado da avaliação seria tendenciosamente negativo, não retratando a verdade, e impactando negativamente na progressão docente. Os comentários revelaram que os professores acham importante a avaliação docente pelo discente para obter o feedback dos alunos, mas com a ressalva de que a mesma deve ser realizada com seriedade e imparcial.

Outros 49 comentários afirmaram que a avaliação só é respondida somente por aqueles alunos que apresentam um desempenho muito bom ou muito ruim. Como já foi mencionado, alunos com desempenho muito ruim, segundo os professores, tendem a responder a pesquisa para prejudicar o professor. Também há opiniões que dizem que alunos com desempenho muito bom tendem a responder a pesquisa elogiando o professor.

Em quarto lugar, com 41 comentários, os docentes discutiram a obrigatoriedade ou não da avaliação por parte dos discentes. A maioria dos docentes considerou a obrigatoriedade da avaliação para melhorar a representatividade/significância da pesquisa. Ao contrário, outros demonstraram preocupação com a obrigatoriedade, pois poderia acarretar numa maior apatia dos alunos em responderem a avaliação, o que os levariam a responder de modo menos responsável, ou de "qualquer jeito".

Em quinto lugar, 39 docentes comentaram sobre o instrumento avaliativo. Alguns apontaram que o questionário da Avaliação do Docente pelo Discente carece de ajustes. As questões que geraram mais controvérsias entre os professores foram as que envolvem o "programa da disciplina" e se o (a) "professor(a) tem aluno(a) de pósgraduação em docência orientada que ministra aulas para a turma". Isso por que, de acordo com os professores, os alunos tendem a responder equivocadamente ou de má fé essas questões. Com relação à apresentação do programa da disciplina com resposta em escala likert (discordo totalmente, discordo em parte, não concordo nem discordo, concordo em parte, concordo totalmente), os docentes argumentam que a apresentação do programa seria um fato com apenas duas situações possíveis: o professor apresentou o programa ou não apresentou, embora possa ter apresentado 
parcialmente. Além disso, os docentes consideram uma falta de consistências nas respostas dessa questão, com alunos respondendo categorias contraditórias em uma mesma turma. Constatou-se, segundo declarações de docentes, que a apresentação do programa da disciplina geralmente se dá na primeira semana de aula, quando muitos alunos faltam às aulas. Além disso, foi sugerido que o próprio sistema de avaliação fizesse o cruzamento dessas informações com o registro da apresentação do programa no Diário de Classe, documento oficial para o registro das aulas. Esse documento também poderia ser utilizado pelo sistema de avaliação para confrontar as respostas de outras questões, como aquela que avalia se o docente cumpriu a ementa da disciplina. Também foram comentadas que algumas questões deveriam ser desdobradas entre duas ou mais questões, como por exemplo a questão que contempla o domínio do conteúdo e o tratamento do conteúdo. Além disso, alguns professores disseram que o questionário não é apropriado para avaliar suas disciplinas, pois as disciplinas envolvem outras dimensões metodológicas, as quais não estão contempladas pelo instrumento.

Outro tema controverso abordado por 29 docentes foi o fato da avaliação ser considerada para progressão. Alguns consideram necessário serem avaliados por seus alunos, mas outros são extremamente contra a utilização da Avaliação para progressão pela própria falta de credibilidade do instrumento, revelada na insignificante participação dos alunos e na falta de seriedade com que eles encaram a avaliação, entre outros.

Além disso, 25 docentes consideraram que as questões da avaliação deveriam ser melhor esclarecidas para os alunos, ou seja, acreditam que os alunos muitas vezes não respondem de forma correta ao questionário ou demonstram falta de seriedade, pois não entendem algumas questões e/ou seus objetos. Toma-se como exemplo a questão "O professor estimula a utilização de materiais complementares (livros, sites, periódicos online, áudio, vídeos, entre outros)". Se o aluno não tiver equilíbrio e consciência de que deve dosar a resposta levando em consideração todos os itens questionado e a possibilidade de aplicabilidade na disciplina, ele pode realizar a avaliação levando em conta apenas um item, seja por considerá-lo mais importante ou 
o menos utilizado pelo professor, resultando em uma avaliação tendenciosa. No entanto, essa questão já foi modificada na última avaliação para "O professor estimula a utilização de materiais complementares", sem citar as opções, pelo fato que em nem todas as disciplinas convém utilizar todos os recursos mencionados e isso estava causando confusão entre os alunos. Outra questão que geralmente causa confusão é se o professor tem aluno de pós-graduação em docência orientada que ministra aulas para a turma. Às vezes, por falta de conhecimento, os alunos confundem docência orientada com monitoria.

Também foi apontado por 23 docentes que deveria haver maior divulgação e conscientização dos alunos sobre a importância da avaliação. Nesse sentido, alguns docentes consideram, por exemplo, que deveria ser ampliado o período da avaliação e que deveria haver uma campanha publicitária de maior impacto, com algum tipo de incentivo aos alunos respondentes, como acesso a alguma plataforma educacional de interesse deles. A avaliação é amplamente divulgada por e-mail, via portal do aluno e no site da UFSM. Mas, de fato, não se observa nenhuma ação na Universidade com relação ao feedback aos alunos que realizam essa avaliação, no que diz respeito à importância da avaliação ou por que ela deve ser realizada. Dentre os comentário foi dito que alguns alunos têm percepção errada sobre essa avaliação, acreditando, por exemplo, que o professor terá aumento de salário se for bem avaliado.

Em relação a avaliação colaborar ou não para a prática docente, 22 professores discutiram o tema de forma que a maioria diz que a avaliação foi importante para reavaliar suas práticas em sala de aula, mas outros expuseram que, apesar de ter o propósito de ajudar os docentes na melhoraria e adequação das aulas, os comentários dos alunos tiveram um efeito negativo em suas práticas docentes.

Dentre os docentes que colaboraram com essa pesquisa, respondendo ao questionário, 16 apontaram que o referido instrumento não contemplava suas respostas, pois elas não seriam apenas "sim" ou "não", mas respostas intermediárias como "em parte", "concordo parcialmente", entre outras. Esse item já foi explicado na metodologia da pesquisa, mas poderia ter sido explicado, de fato, aos respondentes no momento da aplicação da pesquisa. 
Ainda, foi apontado por 10 docentes que somente poderiam participar da Avaliação os alunos que possuíam, no mínimo, 75\% de frequência nas aulas. Os professores argumentaram que os alunos que não participam das aulas não têm condições de avaliar e tendem a dar respostas falsas no instrumento.

Um último tópico que foi apontado por apenas 5 docentes, mas que apesar do menor número, parece ser bastante relevante já que considera a opinião dos alunos apurada pelos professores é que os alunos não têm incentivos de participar da avaliação, pois não há nenhuma mudança ou melhoria nas aulas, mesmo que eles façam críticas e deixem sugestões para os professores. Ou seja, eles não vêem nenhum resultado concreto da avaliação. Pelo fato de ser uma avaliação bastante recente, ainda não há um plano de ações para atuar nas deficiências apontadas pelos alunos. Algumas questões são delicadas de atuar, como por exemplo, professores criticados que precisam melhorar sua forma de ensinar. Muitos docentes não concordam com tais críticas, o que cria uma barreira entre a situação atual e a melhoria. Investigar se, de fato, os alunos têm razão e o docente precisa melhorar sua cátedra, não é algo trivial e envolve uma série de questões que podem gerar diversos problemas de relações pessoais, intra-departamentais, processos administrativos, etc.

\section{CONCLUSÕES E CONSIDERAÇÕES FINAIS}

Esse estudo teve como objetivo avaliar a percepção dos docentes da UFSM com relação a um dos métodos de avaliação interna da instituição, o instrumento de Avaliação do Docente pelo Discente por meio de uma análise descritiva e outras técnicas estatísticas. Foram obtidas informações relevantes para o estudo em questão, principalmente com relação às fragilidades do instrumento segundo a percepção dos docentes, embora a participação docente na pesquisa estivesse abaixo do esperado. Apesar desses apontamentos, os resultados também mostraram que a avaliação tem seus aspectos positivos, pois a maioria dos docentes (70,5\%) está satisfeita com o instrumento de avaliação, assim como a maioria $(91,0 \%)$ incentiva a participação dos seus alunos mesmo com as divergências com relação às críticas recebidas. Além disso, a maioria dos docentes $(71,7 \%)$ está satisfeita com a obrigatoriedade da aplicação da 
avaliação docente pelo discente, o que mostra que os docentes acreditam na importância dessa avaliação.

Para melhorar os resultados da avaliação docente pelo discente, sugere-se:

- aprimorar o questionário, melhorando as questões que estão com problemas de formulação e tornando-o adequado para ser utilizado na progressão docente;

- realizar ações para sensibilizar os docentes a incentivarem seus alunos a participarem da avaliação docente;

- conscientização os alunos sobre a importância da avaliação;

- estudar ações para aumentar o índice de participação dos alunos;

- remover da avaliação as respostas de alunos reprovados por frequência;

- cruzar os resultados da avaliação com os dados registrados no Diário de Classe.

- Sugere-se ainda fazer uma pesquisa de percepção dos alunos quanto à avaliação docente pelo discente, afim de investigar:

- porque houve discordância entre os professores com relação às críticas recebidas pelos alunos, verificar se as causas informadas pelos docentes procedem;

- se o desempenho do aluno na disciplina influencia na avaliação docente;

- se os alunos não levam a sério a avaliação docente;

- porque a maioria dos alunos não participa da avaliação.

Ainda há muito a fazer para melhorar a Avaliação Docente pelo Discente, de tal forma que ela se torne realmente eficiente para os objetivos a que se propõe, como a melhoria da qualidade do ensino, por meio de ações que melhorem as aulas e o desempenho docente.

Os resultados dessa pesquisa poderão vir a permitir a observação, mensuração e análise qualitativa e quantitativa dos motivos pelos quais as opiniões divergem em relação à Avaliação que vem sendo aplicada desde 2016. Estes indicadores podem ser utilizados para promover técnicas de sensibilização e esclarecimento nos docentes que tem opiniões contraditórias a respeito da avaliação. Além disso, podem promover a conscientização da importância da avaliação e estimular uma maior participação dos discentes nas futuras avaliações. Ainda, os resultados podem auxiliar a Comissão Permanente de avaliação (CPA) a aperfeiçoar o instrumento. 


\section{REFERÊNCIAS}

BRASIL. Portaria n. 554 de 20 de junho de 2013, Diretrizes gerais para o processo de avaliação de desempenho para fins de progressão e de promoção dos servidores pertencentes ao Plano de Carreiras e Cargos de Magistério Federal das Instituições Federais de Ensino vinculadas ao Ministério da Educação. Diário Oficial da União, Poder Executivo, Brasília, DF, 23 jul. 2013. Seção 1, p.10.

BRASIL. Lei n. 10.861, de 14 de abril de 2004, Institui o Sistema Nacional de Avaliação da Educação Superior - SINAES e dá outras providências. Diário Oficial da União, Poder Executivo, Brasília, DF, 15 abr. 2004. Seção 1.

BRASIL. Portaria n. 2.051, de 9 de julho de 2004, Regulamenta os procedimentos de avaliação do Sistema Nacional de Avaliação da Educação Superior (SINAES), instituído na Lei no 10.861, de 14 de abril de 2004. Diário Oficial da União, Poder Executivo, Brasília, DF, 12 jul. 2004. Seção 1. p. 16.

MALHOTRA NK. Pesquisa de marketing: uma orientação aplicada. 6. ed. Porto Alegre: Bookman, 2012.

MATUICHUK M, SILVA MC. Avaliação do docente pelo discente na melhoria do desempenho institucional: UTFPR/SIAVI. Ensaio: Avaliação e Políticas Públicas em Educação. 2013;21(n):323-348.

MCDANIEL CD, GATES R. Pesquisa de marketing. São Paulo: Thomson Learning, 2006.

MOTA MC. A importância da comissão própria de avaliação no processo de melhoria da qualidade do ensino nas instituições de ensino superior brasileiras. AMPLIANDO, Revista Científica da Facerb, 2016;3(1):6-22.

RIBEIRO, JLLS. Avaliação das universidades brasileiras as possibilidades de avaliar e as dificuldades de ser avaliado. Avaliação: Revista da Avaliação da Educação Superior. 2011; 16(1):57-71.

UFSM em Números. Disponível em: https://portal.ufsm.br/ufsm-emnumeros/publico/index.html. Acesso em: 30/08/2017. 